\title{
INTERPRETATION OF THE TOTAL MAGNETIC FIELD ANOMALIES MEASURED BY THE CHAMP SATELLITE OVER A PART OF EUROPE AND THE \\ PANNONIAN BASIN
}

4

${ }^{1}$ Geophysics and Space Sciences Department Loránd Eötvös University, Pázmány Péter sétány 1/c., 1117 Budapest, Hungary, e-mail: kisk@ludens.elte.hu ${ }^{2}$ Planetary Geodynamics Laboratory NASA/GFSC, Greenbelt, MD 20771, USA ${ }^{3}$ MOL Hungarian Oil and Gas Co., Budafoki út 79, 1117 Budapest, Hungary

${ }^{4}$ Institute of Geodesy, Cartography and Remote Sensing, Bosnyák tér 5., 1149 Budapest, Hungary ${ }^{5}$ Fractal Partnership, Óda u. 37, 1155 Budapest, Hungary

In this study we interpret the magnetic anomalies at satellite altitude over a part of Europe and the Pannonian Basin. These anomalies are derived from the total magnetic measurements from the CHAMP satellite. The anomalies reduced to an elevation of $324 \mathrm{~km}$. An inversion method is used to interpret the total magnetic anomalies over the Pannonian Basin. A three dimensional triangular model is used in the inversion. Two parameter distributions: Laplacian and Gaussian are investigated. The regularized inversion is numerically calculated with the Simplex and Simulated Annealing methods and the anomalous source is located in the upper crust. A probable source of the magnetization is due to the exsolution of the hematite-ilmenite minerals.

Keywords: $C H A M P$, total magnetic anomalies, Laplacian and Gaussian parameter distributions, regularized inversion, Simplex and Simulated Annealing methods, exsolution of hematite-ilmenite minerals

\section{Introduction}

Satellite altitude magnetic anomalies, while lacking in the ability to measure shortwavelength anomalies, act as a low-pass filter and record the long-wavelength regional magnetic fields. This integrated broad scale field is useful in the interpretation of large and deep structures. Therefore in order to make a sectional interpretation of Western Europe and in detail the Pannonian Basin we employed higher altitude measurements.

The Geoforschungszentrum (GFZ) satellite CHAMP observed the gravity and magnetic fields of the Earth with high accuracy between July 15, 2000 and September 19, 2010. The 
total magnetic field of the Earth was measured by a scalar Overhauser magnetometer with the accuracy of $\pm 0.5 \mathrm{nT}$.

We have previously interpreted CHAMP magnetic anomalies over several different areas (Taylor et al. 2003, 2005 and 2008, Kis et al. 2011).

Our data for this study were measured between January 1 and December 31, 2008. At this time the CHAMP had its elevation of $319-340 \mathrm{~km}$. In our report the total magnetic anomaly field over a part of central Europe and the Pannonian Basin will be interpreted.

Only data whose Kp index was less than or equal to 1. were selected for processing.

After the satellite data were reduced and plotted (Kis et al., 2011) we made a quantitative interpretation using method of Kis et al. (2011) with some modifications. Some parts of the above mentioned phases have been published by Kis et al. (2011). The location of the CHAMP total magnetic measurements is determined by latitude, longitude and radius. The total magnetic anomaly data are derived from the 3D interpolation of the Gaussian weight function. The details of the interpolation are given by Véges (1971) and Kis and Wittmann (1998, 2002).

For the sake of completeness phases $1-3$ will be summarized while the others will be discussed in more detail.

Our analysis is:

1) The data for the forward problem of the inversion are in a spherical polar coordinate system. These total magnetic anomaly data are then transformed from the spherical polar coordinate system into an $x y z$ Cartesian coordinate system;

2) We determined an appropriate forward model for the inversion;

3) A decision on an inversion procedure and the probability distribution of the model parameters was made;

4) Regularization of these reduced data was then completed;

5) Finally an interpretation of these results was carried out using our inversion method.

\section{A review of satellite altitude geomagnetic anomaly interpretations of the tectonics a} section of Central Europe.

The mapped anomalies shown in Fig. 1a reflect the large-scale general tectonic pattern of this region, one of the most complex structural areas on Earth.

The region covered by our CHAMP satellite altitude magnetic anomaly study of central Europe is given in Fig. 1a. This area extends from $0^{\circ}$ to $45^{\circ}$ East Longitude and $40^{\circ}$ to $65^{\circ}$ 
North Latitude. This sector is centered on central Europe. Satellite altitude magnetic data are only capable of mapping large scale (generally assumed to be equal to the altitude of the satellite) and deep structures. The mapped anomalies, given in Fig. 1a, reflect the large-scale general tectonic pattern of this region.

We will briefly discuss a regional interpretation of the major magnetic anomalies and a more detailed one for the anomalies over the Pannonian Basin. There are several major structures in our study area. The northwest-southeast trending Tornquist-Tessiyre Zone (TTZ), a suture, dominates central Europe revealing the collision zone between the West European Craton (Avalonia) and the Baltic Shield (Baltica). Therefore, the TTZ is a structural boundary between the Paleozoic or western part of Europe and the Proterozoic or eastern sector. The magnetic signature of this large suture is mapped by the satellite altitude data as two northwest-southeast trending anomalies with the negative to the southeast and the positive to the northeast (Fig. 1a) (Taylor and Ravat, 1995).

Avalonia is a mélange of Caledonian, Hercynican (Variscan) and Alpine terrains; while Baltica is essentially a complex of Pre-Cambrian structures. Three major tectonic plates converge to form the TTZ. The northwest sector of Avalonia is comprised of Caledonian and Hercynican terranes. Initially this feature collided with Baltica in the late Ordoviciqan (Trench and Torsvik, 1992). Subsequently, the combined Caledonian (Hercynian) Baltica block merged with the Alpine/Carpathian plate. The Alpine/Carpathian block came from the south and abuts the Rhenohercynian and Saxothoringian Zones which acted as a buffer between these two joined plates. This Alpine/Carpathian segment was added during the major collision between the Eurasian and the African plates in the Tertiary. A complex pattern of compression and extension resulted from this merger. See Aubouin (1980) and Blundell et al. (1992) for a general description and Pharaoh (1999) and Guterch et al. (1986) for a more detailed interpretation.

There have been several magnetic studies of the TTZ using both ground based and satellite data. Ground based magnetic interpretations of this region are given by Banka et al. (2002) and Grabowska and Bojdys (2004), they emphasized the distinct border of this feature. While satellite altitude data reveal a broader structural pattern (Taylor and Ravat, 1995 and 1996; Pucher and Wonik, 1996, and 1998). Taylor and Ravat (1995) found that this suture represented the juxtaposition of two different plates the Avalonia section with a younger and thinner crust and higher than average heat flow had a negative anomaly while the older, Baltica plate has a thicker and lower than average heat flow and a positive anomaly. This region was modeled by two bodies with Avalonia having a reverse magnetization on the 
Baltica a normal magnetization. However, Pucher and Wonik (1996, 1998) models are significant different in the number and shape of these magnetized bodies while having a somewhat different direction of the magnetization. However, that both agree the Avalonia and Baltic blocks have a reverse magnetization for the former and a positive for the latter.

The two remaining large circular satellite magnetic anomalies circular and (Fig. 1a) were interpreted to be the result of varying crustal thickness, one negative $(<-20 \mathrm{nT})$ over the southern part of the Finnish Svecofennian shield (Taylor et al., 2005, 44 km crustal thickness) and the other positive (> $22 \mathrm{nT}$ ) with a greater than $50 \mathrm{~km}$ thick crust is the Kursk Magnetic Anomaly (KMA, Taylor and Frawley, 1987, Taylor et al. 2003).

Figure. 1b shows a subsection of the anomaly field (Fig. 1a) and is centered on the Pannonian Basin. The data processing for the Pannonian Basin is the same as the regional field. CHAMP anomaly data are transformed from the spherical polar coordinate system to the Cartesian coordinate system. The steps of transformation are summarized in the published paper of Kis et al. (2011). Only those anomaly data which cover the Pannonian Basin are transformed. We will quantitatively invert and interpret these data in more detail.

The Pannonian Basin formed in the Miocene when elements of the African plate collided with the Eurasian plate this initiated a complex series of tectonic interactions. From the northeast thin European continental crust was subducted beneath the Dinarides plate. North-south directed forces produced both compression and east-west extension. The subducting East Carpathian slab then rolled back allowing asthenospheric material to rise under the lower crust producing a back arc extension and thermal up lift of the Carpathian crust. Subsequently this produced extensional collapse in these terraines causing crustal thinning, local compression, rifting, northeast-southwest shear faulting and basin formation. This is description is oversimplified and serves to give some indication of the complexity of this region, see; Horvath (1993), Morley (1993), Huismans et al. (2002) and Lorinczi and Houseman (2010) and references therein.

The magnetic anomaly map at an altitude of $324 \mathrm{~km}$ (Fig. 1b) shows a large NW-SE oriented negative anomaly in the middle of the Pannonian Basin. To model this anomaly in our inversion we used a triangular polygonal prism. The inversion model is shown by Fig. 2 . Plouff's (1976) method was used to compute the field of this model. The selection of this model was based on our interpretation of the vertical gradient map of the CHAMP total magnetic anomaly field (Kis et al. 2011). The forward model has a reverse magnetization of minus $1.5 \mathrm{~A} / \mathrm{m}$, with an inclination and declination of $-60^{\circ}$ and $60^{\circ}$, respectively. These values were determined by Taylor et al. (2005) and applied by Kis et al. (2011). 

inversion procedures. The Bayesian inference procedure has been applied which is expressed by the following equation

where $\mathrm{p}(\mathbf{m} \mid \mathbf{d})$ is the a posteriori conditional probability density, $\mathrm{p}(\mathbf{d} \mid \mathbf{m})$ is the likelihood probability density, and $\mathrm{p}(\mathbf{m})$ is the a priori probability density. The Bayesian inversion is widely used in the inversion procedures and is summarized by Duijndam (1988a, 1988b), Menke (1989) and Sen and Stoffa (1995). In the above equation vector $\mathbf{m}$ indicates the determined model parameters $\left[\left(\mathrm{x}_{1}, \mathrm{y}_{1}\right),\left(\mathrm{x}_{2}, \mathrm{y}_{2}\right),\left(\mathrm{x}_{3}, \mathrm{y}_{3}\right)\right.$, and top and base depths are $\mathrm{Z}_{\mathrm{T}}$ and $\mathrm{Z}_{\mathrm{B}}$, respectively], vector $\mathbf{d}$ indicates the measured data. multiplication of a priori and likelihood probability densities. Disregarding the constant multipliers the $a$ posteriori probability is given as:

$$
p^{\text {a posteriori }} \propto \exp \left(-\frac{1}{2} \mathbf{( n - m ^ { \text { a priori } } \rceil} \mathbf{C}_{m}^{-1} \mathbf{( n - m ^ { \text { a priori } }}\right)
$$

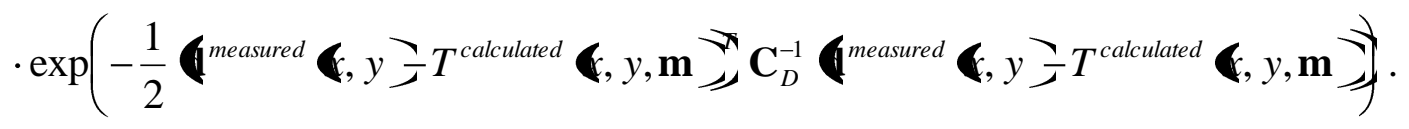

The multivariate Laplace a posteriori probability density distribution is given in the following 161 form:

$$
p^{\text {a posteriori }} \propto \exp \left(-\frac{\left|\mathbf{m}-\mathbf{m}^{\text {a priori }}\right|}{\mathbf{C}_{m}^{1 / 2}}\right) \cdot \exp \left(\frac{-\left|\mathbf{d}^{\text {measured }} \boldsymbol{\&}, y-T^{\text {calculated }} \boldsymbol{\&}, y, \mathbf{m}\right\rangle \mid}{\mathbf{C}_{D}^{1 / 2}}\right),
$$

164 in which the a posteriori probability can be expressed as the multiplication of the a priori and the likelihood functions. We disregard the constant multipliers. The superscript indicate the measured and calculated (forward model) data. 


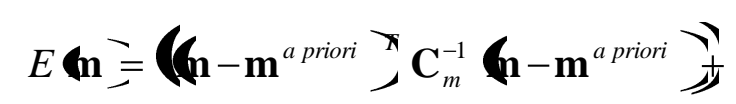

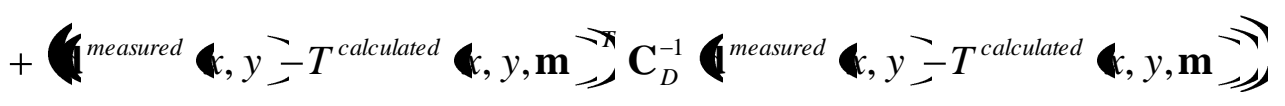

which is for the multivariate Gaussian function and

$$
E \mathbf{m})\left(\frac{\left|\mathbf{m}-\mathbf{m}^{\text {a priori }}\right|}{\mathbf{C}_{m}^{1 / 2}}\right)+\left(\frac{\left|\mathbf{d}^{\text {measured }} \varangle, y-T^{\text {calculated }} \varangle, y, \mathbf{m}\right\rangle}{\mathbf{C}_{D}^{1 / 2}}\right)
$$

174

which is for the multivariate Laplacian function. In the objective functions $\mathbf{C}_{m}$ and $\mathbf{C}_{\mathrm{D}}$ are the a priori and the data covariance matrices, respectively.

\section{Regularization}

The minimum problem generally appears in various fields of science and engineering. The solution of the minimum problem is often approximated by numerical methods. The aim of regularization is to construct the $\Omega(\mathbf{m})$ or $\lambda \Omega(\mathbf{m})$ functions which help the determination of the minimum of the $E(\mathbf{m})$ function, where $\lambda$ is the regularization parameter. Regularization is discussed in details by Tikhonov and Arsenin (1977).

Let us suppose there is an element $\mathbf{m}_{0}$ of the $F$ set, where $E(\mathbf{m})$ has its smallest value, that is

$$
\left.\inf E \mathbf{( n )} E \mathbf{m}_{0}\right) E_{0} \quad \text { where } \mathbf{m} \in F .
$$

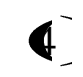

The minimizing sequence $\left\{\mathbf{m}_{n}\right\}$ converges to the element $\mathbf{m}_{0}$. In this case $E(\mathbf{m})$ is regularized. The function $\Omega\left(\mathbf{m}_{\mathrm{n}}\right)$ is often referred to as a stabilizing function. It has the property of $\Omega(\mathbf{m})$ is a continuous non-negative function.

There are several possibilities of finding the appropriate stabilizing function. In our present paper the $\Omega(\mathbf{m})=\lambda\left(\mathbf{m}_{\mathrm{i}-1}-\mathbf{m}_{\mathrm{i}}\right)^{2}$ and $\Omega(\mathbf{m})=\lambda\left|\mathbf{m}_{\mathrm{i}-1}-\mathbf{m}_{\mathrm{i}}\right|$ functions are selected as 
stabilizing functions for the case of the Gaussian distribution and Laplacian distribution model parameters, respectively. The regularized objective functions can be expressed in the forms of

$$
E \mathbf{m}=\left(\mathbf{n}-\mathbf{m}^{\text {a priori }}\right) \mathbf{C}_{m}^{-1}\left(\mathbf{n}-\mathbf{m}^{\text {a priori }}\right)_{j}^{\prime}
$$

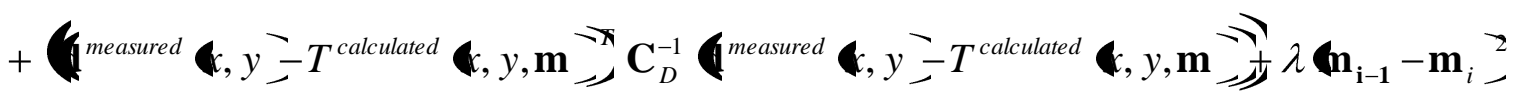

and

$E \mathbf{( n})\left(\frac{\left|\mathbf{m}-\mathbf{m}^{\text {a priori }}\right|}{\mathbf{C}_{m}^{1 / 2}}\right)+\left(\frac{\left|\mathbf{d}^{\text {measured }} \ll, y-T^{\text {calculated }} \ll, y, \mathbf{m}\right\rangle}{\mathbf{C}_{D}^{1 / 2}}\right)+\lambda\left|\mathbf{m}_{\mathbf{i}-\mathbf{1}}-\mathbf{m}_{\mathbf{i}}\right|$,

respectively.

The regularized minimum problem was solved by a numerical method: the Simplex method summarized by Walsh (1975) and the Simulated Annealing procedure by Kirkpatrick et al. (1983) and Sen and Stoffa (1995).

The minimum problem was solved by the $\mathrm{L}_{1}$ norm in the case of the Laplace distribution of the model parameters and $\mathrm{L}_{2}$ norm in the case of the Gaussian distribution of the model parameters.

Figs. 3 and 4 show the regularized objective functions and the regularization functions versus the iterative step in a logarithmic scale. In the cases we show the regularized minimum problem was solved by the Simulated Annealing method where the regularization parameter was $\lambda=0,1,10$ and 100 . It can be deduced that the appropriate choice for the parameter $\lambda$ is in the interval 1-10. This was determined after some trial and error calculation of several synthetic examples. The decrease of the objective and regularization functions in not appropriate for the case of $\lambda=100$. In the case of the Gaussian parameter distribution the regularization function shows some oscillations.

Similar results can be obtained from the regulated inversion procedure calculated by the Simplex method. 
At an elevation of $324 \mathrm{~km}$ a relatively large total magnetic field anomaly lies along the central part of the Pannonian Basin (Fig. 1b). The magnitude of this NW-SE trending negative anomaly is $-13 \mathrm{nT}$. A subsection of Fig. 1b, extending between $45^{\circ}-49^{\circ}$ latitude and $15^{\circ}-24^{\circ}$ longitude contains the main section of this anomaly and it is qualitative interpreted.

The values of the model parameter we determined are summarized in the Table 1.

The source of this anomaly is in the upper crust according to these derived depths. We propose that the anomaly is probably caused by a metamorphic complex situated in the upper crust.

Similar large magnitude negative anomalies were discovered over the Mid-Proterozoic granulites in southwestern Sweden (McEnroe et al. 2001), Proterozoic Åna Sira anorthosite in Rogaland Norway (McEnroe et al. 2004, 2005 and Robinson et al. 2002) and in the Modum district of Southern Norway (Fabian et al. 2008). These results suggest that the stabile remanent magnetization is produced by the exsolution of the hematite-ilmenite minerals. The contact zones around these minerals can produce a strong ferromagnetic effect.

The Hungarian Balaton Highlands xenolites carry some indications on the probable rocks of the upper crust (Dégi et al. 2009, Embey-Isztin et al. 2001, 2003; Dobosi et al. 2002). We propose that the exsolution of the hematite-ilmenite minerals also is found in the upper crust of the Pannonian Basin.

\section{References}

Aubouin J 1980: Episodes, 1, 3-8.

Banka D, Pharaoh T C, Williamson J P 2002: Tectonophys., 360, 23-45.

Blundell D, Freeman R, Mueller S (Eds.) 1992: A Continent Revealed: The European Geotraverse, Cambridge University Press.

Dégi J, Abart R, Török K, Rhede D, Petrishcheva E 2009: Miner. Perol. 95, 219-234.

Dobosi G, Kempton P D, Downes H, Embey-Isztin A, Thirlwall M, Greenwood P 2003:

Contrib. Mineral. Petrol., 144, 671-683.

Duijndam A J W 1988a: Geophys. Prosp., 36, 878-898.

Duijndam A J W 1988b: Geophys. Prosp., 36, 899-918.

Embey-Isztin A, Dobosi G, Altherr R, Meyer H-P 2001: Tectonophys. 331, 283-305.

Embey-Isztin A, Downes H, Kempton P D, Dobosi G, Thirlwall M 2003: Contrib. Mineral.

Petrol. 144, 652-670. 
262 Fabian K, McEnroe S A, Robinson P, Shcherbakov V P 2008: Earth Planet. Sci. Lett. 268, 263 339-353.

264 Grabowska T, Bojdys G 2004: Tectonophys., 383, 15-28.

265 Guterch A, Grad M, Materzok B, Perchu E 1986: Tectonophys. 128, 251-279.

266 Horvath F, 1993: Tectonophys. 226, 333-357.

267 Huismans R S, Podladchikov Y Y, Cloetingh S A P L 2002: EGU Stephan Mueller Special 268 Publication Series 3, 41-63.

269 Kirkpatrick S, Gelatt Jr C D, Vecchi N P 1983: Science, 220, 671-680.

270 Kis K I, Wittmann G 1998: J. Appl. Geophys., 39, 11-24.

271 Kis K I, Witmann G 2002: J. Geodyn. 33, 117-129.

272 Kis K I, Taylor P T, Wittmann G, Toronyi B, Puszta S 2011: J. Appl. Geoph.. 75, 412-418.

273 Lorinczi P, Houseman G 2010: Tectonophys. 492, 73-87.

274 McEnroe S A, Harrison R J, Robinson P, Golla U, Jercinovic M J 2001: J. Geophys. Res., 106 275 (B12) 30,523-30,546.

276 McEnroe S A, Langenhorst F, Robinson P, Bromiley G D, Shaw C S J 2004: Earth Planet. 277 Sci. Lett., 226, 175-192.

278 McEnroe S A, Harrison R J, Jackson M J, Hirt A M, Robinson P, Langenhorst F, Heidelbach 279 F, Kasama T, Putnis A, Brown L L, Golla-Schindler U 2005: J. Phys. Conf. Ser. 17, 154-167. 280 Menke W 1989: Geophysical Data Analysis: Discrete Inverse Theory. Academic Press, Inc. 281 San Diego, New York, Boston, Sydney, Tokyo, Toronto.

282 Morley C K 1993: Tectonophys. 226, 359-376.

283 Pharaoh T C 1999: Tectonophys, 3, 17-41.

284 Plouff D 1976: Geophys., 41, 727-741.

285 Pucher R, Wonik T 1996: J. Appl. Geophys., 36, 213-216.

286 Pucher R, Wonik T 1998: Phys. Chem. Earth, 23, 981-985.

287 Robinson P, Harrison R J, McEnroe S A, Hargraves B B 2002: Nature, 418, 517-520.

288 Sen M, Stoffa P L 1995: Global Optimization Methods in Geophysical Inversion, Elsevier, 289 Amsterdam, Lausanne, New York, Oxford, Shannon, Tokyo.

290 Taylor P T, Frawley J J 1987: Phys. Earth Planet. Int., 45, 255-265.

291 Taylor P T, Ravat D 1995: J. Appl. Geophys., 34, 83-1.

292 Taylor P T, Ravat D 1996: J. Appl. Geophys., 36, 217-219.

293 Taylor, P T, Frawley, J J, Kim, H R, von Frese, R, Kim, J W 2003: Comparing Magsat,

294 Ørsted and CHAMP Crustal Magnetic Anomaly Data over the Kursk Magnetic Anomaly, 295 Russia, In Reigber Ch, Lühr H . Schwintzer J (Eds.), First CHAMP Mission Results for 
296 Gravity, Magnetic and Atmospheric Studies, Springer-Verlag, Berlin, Heidelberg, New York, $297 \quad 302-308$.

298 Taylor P T, Kis K I, Frese von R R B, Korhonen J V, Wittmann G, Kim H R, Potts L V 2005: 299 Effects of varying crustal thickness on CHAMP geopotential data, In: Reigber Ch, Lühr H . 300 Schwintzer J (Eds.), Earth Observation with CHAMP, Springer-Verlag, Berlin, Heidelberg, 301 New York, 279-286.

302 Taylor P T, Kim H R, Kutina J, Johnson G L 2008: Earth, Planets and Space, 60, 497-503. 303 Tikhonov A N, Arsenin V Y 1977: Solutions of Ill-Posed Problems. John Wiley \& Sons New 304 York Toronto London Sydney.

305 Trench, A, Torsvik T H 1992: Special Paper: The closure of the Iapetus Ocean and the 306 Tornquist Sea: new palaeomagnetic data, Journal Geological Society London, 149, 863-66.

307 Véges I 1971: Pure Appl. Geophys., 78, 5-17.

308 Walsh G R 1975: Methods of Optimization, John Willey \& Sons, London, New York, Sidney, 309 Toronto.

Fig.1. (a) Total magnetic field anomaly map at $324 \mathrm{~km}$ elevation over a part of Europe, plotted in an Albers' equal area projection, anomalies are given in nT with a range of 24 grey levels and a 2 nT contour interval; (b) total magnetic field anomaly over the Pannonian Basin, plotted in an Albers' equal area projection at $324 \mathrm{~km}$ elevation, anomalies are given in $\mathrm{nT}$ with a range of 16 grey levels and a $1 \mathrm{nT}$ the contour interval, inner frame outlines the region of our inversion study.

Fig. 2. Three dimensional triangular model of the magnetic source body which was used as the forward model of the inversion procedure; upper and lower depths are indicated by $\mathrm{Z}_{\mathrm{T}}$ and $\mathrm{Z}_{\mathrm{U}}$, respectively, the triangular base is given by three coordinate pairs: $\left(x_{1}, y_{1}\right),\left(x_{2}, y_{2}\right),\left(x_{3}, y_{3}\right)$.

Fig. 3. The objective and regularization functions versus the iterative step for the parameter $\lambda=0,1,10$ and 100, the functions are plotted with the same logarithmic scale; the minimum problem was solved by the Simulated Annealing method and the model parameters have a Laplacian distribution. 
329 Fig. 4. The objective and regularization functions versus the iterative step for the parameter $330 \lambda=0,1,10$ and 100, the functions are plotted with the same logarithmic scale; the minimum 331 problem was solved by the Simulated Annealing method and the model parameters have 332 Gaussian distribution.

334 Table 1.Determined model parameters by Simples and Simulated Annealing methods in the 335 case of the Gaussian and Laplace distributions 